\title{
SYNOPSIS
}

News

$\bullet$

AnAlysis

$\bullet$

Practice

\section{Drug Regulation}

\section{Patient demand and politics push Herceptin forward}

The decision of some provinces to pay for the extended use of trastuzumab (Herceptin) in breast cancer treatment is being met with relief by patients and ambivalence by some analysts.

Trastuzumab has been used since 1999 in hospital settings to treat metastatic breast cancer.

This spring, the US Food and Drug Administration extended the drug's use after two phase 3 trials of the drug in women with early-stage HER2 positive breast cancer showed impressive interim results in reducing disease recurrence (see Box).

Excitement over the findings focused media attention on patients with nonmetastatic cancers who were denied access to the drug in Canada. Roughly 25\% of breast cancers - or 5000 newly diagnosed cases in Canada - are HER-2 positive.

Roche Canada, the drug's licensee in Canada for California-based Genentech Inc., plans to submit a new-use application for priority (180-day rather than 300-day) review by Health Canada.

As of July 22, 5 provinces have expanded funding for trastuzumab to include nonmetastatic breast cancer, despite the annual cost per patient of $\$ 35000-\$ 45000$.

British Columbia, Ontario Saskatchewan and Quebec will cover trastuzumab therapy for all eligible patients. Nova Scotia and PEI are extending availability on a case-by-case basis.

The level of hype over trastuzumab seems premature to observers such as Sharon Batt, a breast cancer survivor and a Canadian Institutes of Health Research trainee in the ethics of health research and policy. In the absence of peer-reviewed and published findings, a completed safety analysis or a costbenefit analysis of trastuzumab as front-line treatment, it's all but impossible to make a rational decision on whether the drug should be made widely available, Batt says.

She adds: "I don't think it's necessarily premature for doctors who are familiar with the drug to prescribe it off-label for individual cases."

Other experts note that drug funding decisions are often made on the basis of incomplete information and are affected by factors such as patient demand and publicity.

"It's an intersection of politics, human emotion and science. It always has been," says University of Toronto associate professor of public health science Dr. Susan Bondy. "The whole medical establishment has struggled with issues around these things that are incredibly expensive. They've tried to come up with the scientific rationale for releasing these ... drugs because they know the public wants [them]."

Dr. Douglas Martin, associate professor of health policy, management and evaluation at the University of Toronto Joint Centre for Bioethics, describes a lack of "substantive principles" on which to base funding decisions for new and costly treat- ments. "For example, if you have a cancer drug that can provide a 2 -month increase in survival for patients with metastatic prostate cancer, many patients will think it's worthwhile and quite a few oncologists will think it's worthwhile to fund.

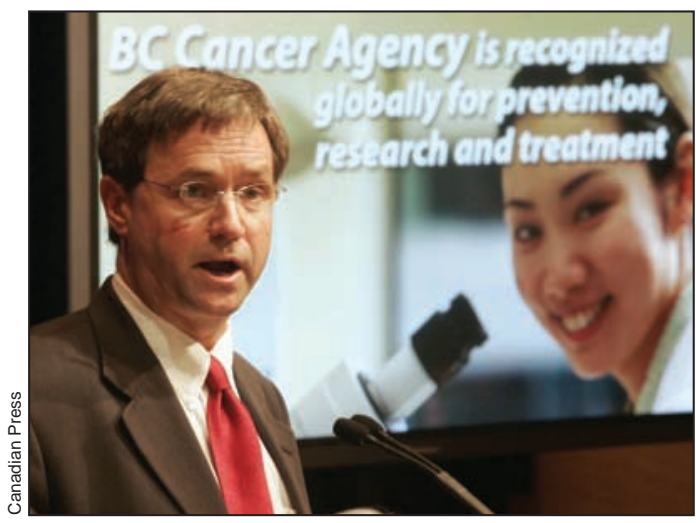

On July 11 BC Health Minister George Abbott announced wider access to Herceptin

But I'm not sure a majority of Canadian taxpayers would.

For patients who have been waiting for trastuzumab, there is no such ambivalence. Allyson Barnett-Cowan, director of faith, worship and ministry for the Toronto-based national office of the Anglican Church of Canada, had a small lump removed from her breast last September and was informed by her physician in mid-June that trastuzumab was the preferred course of treatment.

"But I'm not mortgaging my house or feeling desperate because within the time frame that I need, it's going to be covered by OHIP," the 55-year-old says. "I'm not anxious about it any- 


\section{Box 1: HER-2 and Herceptin}

- What is HER-2 (human epidermal growth factor receptor 2)? Cell growth is controlled in part by growth factor receptors in cell walls. The HER-2 gene regulates the expression of HER-2 receptors. Patients considered to be HER-2 positive have HER-2 gene amplification. About $25 \%$ of patients with breast cancer have HER-2 gene amplification. These patients have an increased risk of metastases, shorter times to relapse and reduced overall survival.

\section{- What is Herceptin?}

Herceptin (trastuzumab) is a monoclonal antibody that inactivates HER-2 receptors, attracts killer cells and slows tumour growth.

\section{- Are there clinical trials of Herceptin?}

Currently, 27 ongoing clinical trials are listed at http://clinicaltrials.gov; several are recruiting patients in Canada. Most are for treatment of breast cancer (including Stage I, II and IIIA), but trials are also ongoing for trastuzumab therapy in colon cancer, sarcoma, osteosarcoma and endometrial cancer.

In an interim analysis of two unpublished trials involving women with Phase II and III breast cancers (phase-3 trials) the rate of disease recurrence over 4 years was $33 \%$ in women treated with chemotherapy alone and $15 \%$ in women treated with chemotherapy and trastuzumab. Adverse effects included cardiac dysfunction.

\section{- Ana Cartagena, University of Manitoba, Class of 2008}

more. What makes me anxious is the [media] coverage about trastuzumab, which makes it sound as if you're going to die if you don't get it right away."

The drug is also believed to be effective in women 6 months or more after completing chemotherapy, meaning that women who currently have or recently had breast cancer will now want to be tested for HER-2.

Although some provinces and oncologists routinely test for HER-2, many don't. This means that a rash of testing will be required to determine if these women are eligible. The test involves a biopsy of tumour tissue being sent to a pathology lab, a problematic prospect given the nation-wide shortage of pathologists. - Wayne Kondro, Ottawa and Barbara Sibbald, CMAJ

\section{BMA House caught in the blast}

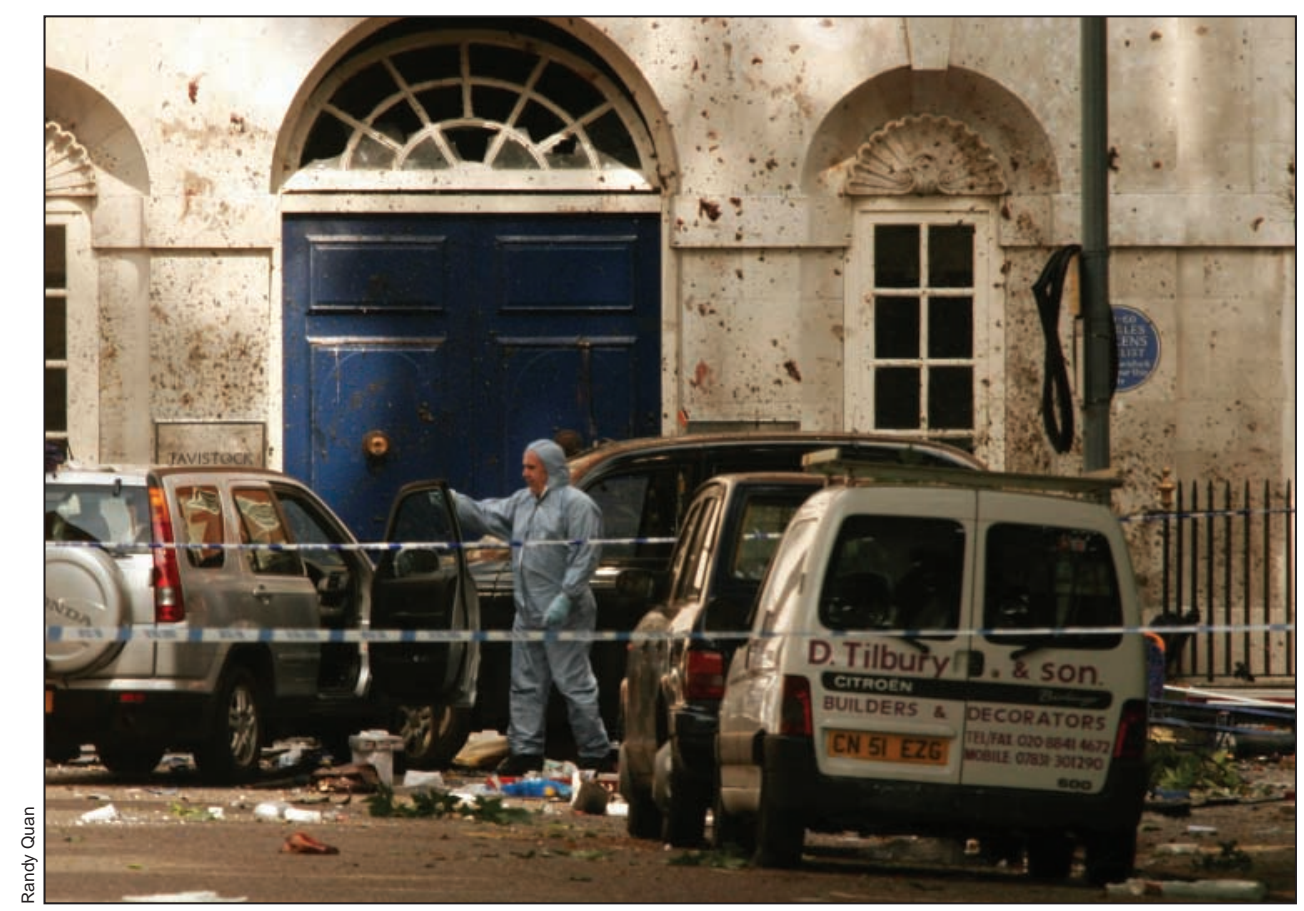

BMA House staff were first-hand witnesses and helpers in the July 7 London bombings. The bomb that destroyed the number 30 bus in Tavistock Square exploded directly outside BMA House, killing 13 and spreading "blood and flesh on the walls of BMA House," wrote Kieran Walsh (BMJ 2005;331:127). Physicians in the building helped the wounded before ambulances arrived. $B M J$ editor Fiona Godlee commended staff on their efforts to produce the journal without interruption from a contingency site as the "best answer to those who would tear our world apart" (BMJ 2005;331:0-g). — Sally Murray, CMAJ 